\title{
Heat Acclimatization, Cooling Strategies, and Hydration during an Ultra-Trail in Warm and Humid Conditions
}

\author{
Nicolas Bouscaren ${ }^{1,2, *}$, Robin Faricier ${ }^{2}$, Guillaume Y. Millet ${ }^{2,3,+}+\mathbb{C}$ and Sébastien Racinais ${ }^{4,+}$ \\ 1 Inserm CIC1410, CHU Réunion, 97448 Saint Pierre, France \\ 2 Inter-University Laboratory of Human Movement Biology, UJM-Saint-Etienne, Univ Lyon, EA 7424, \\ 42023 Saint-Etienne, France; robinfaricier@live.fr (R.F.); guillaume.millet@univ-st-etienne.fr (G.Y.M.) \\ 3 Institut Universitaire de France (IUF), 75231 Paris, France \\ 4 Research and Scientific Support Department, Aspetar Orthopedic and Sports Medicine Hospital, \\ Doha 29222, Qatar; Sebastien.Racinais@aspetar.com \\ * Correspondence: nicolas.bouscaren@chu-reunion.fr; Tel.: +33-262-719-830 \\ + These authors contributed equally to this work.
}

Citation: Bouscaren, N.; Faricier, R.; Millet, G.Y.; Racinais, S. Heat Acclimatization, Cooling Strategies, and Hydration during an Ultra-Trail in Warm and Humid Conditions. Nutrients 2021, 13, 1085. https:// doi.org/10.3390/nu13041085

Academic Editor: William M. Adams

Received: 17 February 2021

Accepted: 24 March 2021

Published: 26 March 2021

Publisher's Note: MDPI stays neutral with regard to jurisdictional claims in published maps and institutional affiliations.

Copyright: () 2021 by the authors. Licensee MDPI, Basel, Switzerland. This article is an open access article distributed under the terms and conditions of the Creative Commons Attribution (CC BY) license (https:// creativecommons.org/licenses/by/ $4.0 /)$.

\begin{abstract}
The aim of this study was to assess the history of exertional heat illness (EHI), heat preparation, cooling strategies, heat related symptoms, and hydration during an ultra-endurance running event in a warm and humid environment. This survey-based study was open to all people who participated in one of the three ultra-endurance races of the Grand Raid de la Réunion. Ambient temperature and relative humidity were $18.6 \pm 5.7^{\circ} \mathrm{C}\left(\max =29.7^{\circ} \mathrm{C}\right)$ and $74 \pm 17 \%$, respectively. A total of 3317 runners ( $56 \%$ of the total eligible population) participated in the study. Overall, $78 \%$ of the runners declared a history of heat-related symptoms while training or competing, and $1.9 \%$ reported a previous diagnosis of EHI. Only $24.3 \%$ of study participants living in temperate climates declared having trained in the heat before the races, and $45.1 \%$ of all respondents reported a cooling strategy during the races. Three quarter of all participants declared a hydration strategy. The planned hydration volume was $663 \pm 240 \mathrm{~mL} / \mathrm{h}$. Fifty-nine percent of the runners had enriched their food or drink with sodium during the race. The present study shows that ultra-endurance runners have a wide variability of hydration and heat preparation strategies. Understandings of heat stress repercussions in ultra-endurance running need to be improved by specific field research.
\end{abstract}

Keywords: hot temperature; hydration; dehydration; electrolyte balance; body temperature regulation; acclimatization; ultra-endurance running; running

\section{Introduction}

Hot and humid ambient conditions impair prolonged exercise capacity and may favor exertional heat illness (EHI) [1,2]. Its most severe form, exertional heat stroke (EHS), is characterized by a core body temperature above $40.5^{\circ} \mathrm{C}$ associated with central nervous system dysfunction (delirium, convulsions, coma) [3,4]. EHS is considered the second most common cause of sport- and exercise-related sudden death, after cardiac conditions [5]. Thus, several guidelines regarding training and competing in the heat have been published $[6,7]$. These guidelines are mostly based on laboratory studies [6] and are limited to running events up to the marathon distance. In other words, they may not apply to ultra-endurance sport, defined in the present paper as any event longer than $6 \mathrm{~h}[8,9]$. In ultra-endurance sports, the thermoregulation and hydration challenges are different compared to shorter exercises due to the moderate intensity but prolonged duration, sometimes associated with exotic destinations, hot or warm environments (desert, tropical climate), and with high prevalence of digestive disorders and pathological processes in various organs such as skeletal muscles, heart, kidneys, and immune and endocrine systems [9-11]. Because of these specificities, the transposition of current knowledge and guidelines for road-races up to marathon toward ultra-endurance running is hazardous $[9,10,12]$. 
With the growing popularity of ultra-endurance events, attention to the unique needs of this population becomes increasingly important [13]. Only a few studies have focused on the influence of heat on performance [14], exercise-associated hyponatremia [15,16], or hydration requirements [17-19] in ultra-endurance events. Areas of uncertainty remain regarding thermoregulatory function, EHI prevalence, and health impairment during ultra-endurance running events in warm or hot conditions [1,13,19]. Moreover, despite the well-accepted benefits of heat acclimatization and cooling strategies before running in hot and humid conditions [6,20], it remains unknown whether ultra-endurance runners follow those guidelines from classical endurance activities.

Moreover, debates continue as to how endurance athletes should hydrate during exercise, i.e., ad libitum/drinking to thirst vs. pre-programmed drinking schedule [21]. For Kenefick et al. [21], drinking to thirst is more applicable for short-duration endurance exercise (<90 $\mathrm{min}$ ), whereas a programmed drinking strategy should be tailored to prevent body mass losses or gains of $\pm 2 \%$ during activities longer than $2 \mathrm{~h}$ in duration, especially if they take place in warm or hot environments. For Hoffman et al. [12], hydration guidelines suitable for short periods of exercise in classical endurance events are not appropriate for ultra-endurance activities and may even cause harm. Hyperhydration can potentially cause the serious complication of exercise associated hyponatremia, so ultra-endurance athletes have been advised to avoid drinking beyond the dictate to thirst [12]. In addition, while the sodium consumed with a typical race diet appears to be adequate to replace losses and avoid salt-depletion in ultra-endurance [22,23], hydration guidelines recommend ingestion of sodium during endurance exercise, and use of supplementation has been a common practice among ultra-endurance athletes [24].

Given the lack of information about heat mitigation strategies in ultra-endurance runners before a race in a tropical environment and the controversies about hydration and sodium supplementation during endurance exercise, the aim of the current study was to survey heat preparation, cooling strategies, and heat-related symptoms (HRS) and to focus on hydration and sodium intake during an ultra-endurance running event in warm and humid environment.

\section{Materials and Methods}

\subsection{Study Design}

This survey-based cross-sectional study was open to all people who participated in one of the three races of the 2019 edition of the Grand Raid de la Réunion. A survey was distributed before and after the race. E-versions were transmitted by the organizing committee through a mailing-list. A hard copy of the pre-race survey was also available at race-bib collection.

\subsection{Ethics Approval}

This study was approved by the Saint-Etienne University Hospital ethics committee (\#IRBN 572019/CHUSTE) and registered in ClinicalTrials.gov (\#NCT04136925). The data were collected, recorded, and stored after obtained consent from the research subjects and were included in the register of processing activities of the Réunion Island University Hospital Center.

\subsection{Characteristics of the Races}

The event was held in Réunion Island (a tropical island in the Indian Ocean) and included three races: La Diagonale des Fous (DDF; 2900 runners, 165 km, 9576 m of positive and negative elevation, 2019 finish time range (23:33:45-66:04:00)); Le Trail de Bourbon (TDB; 1600 runners, $111 \mathrm{~km}, 6433$ m elevation, (15:34:56-41:54:16)); and La Mascareignes (MAS; 1700 runners, 65 km, 3505 m elevation, (07:43:55-20:23:19)). Environmental conditions measured across 8 weather stations distributed along the three running courses reported a temperature of $18.6 \pm 5.7^{\circ} \mathrm{C}$ (range: 3.6 to $29.7^{\circ} \mathrm{C}$ ), a relative humidity of $74 \pm 17 \%$ 
(5 to $100 \%$ ), a dew point of $13.0 \pm 5.9^{\circ} \mathrm{C}\left(-24.7\right.$ to $\left.23.4{ }^{\circ} \mathrm{C}\right)$, and a solar radiation of $87 \pm 116^{\circ} \mathrm{J} / \mathrm{cm}^{2}\left(0\right.$ to $\left.402^{\circ} \mathrm{J} / \mathrm{cm}^{2}\right)$.

\subsection{Participants}

A total of 3317 runners participated in the study, representing $56 \%$ of the total eligible population. Sixty-nine percent $(n=2286)$ of study participants completed the pre-race survey, and $62 \%(n=2050)$ completed the post-race survey. Overall, 1763 respondents took part in the $165-\mathrm{km}$ race, 882 in the $65-\mathrm{km}$ race, and 665 in the $111-\mathrm{km}$ race; $83 \%$ of the responders (both pre- and post-race survey) were finishers. The sex ratio was 5:1 for men, and the mean age of runners was 42.2 years (representative of the starters). The climate of residence was temperate or continental for $55 \%$ of runners, and hot (tropical or dry) for $45 \%$ of runners. The demographic, morphological, and training characteristics of the participants are presented in Table 1.

Table 1. Characteristics of study participants in the Grand Raid de la Réunion runners by total sample and according to the race.

\begin{tabular}{|c|c|c|c|c|}
\hline Variables & Total & La Mascareignes & Le Trail De Bourbon & La Diagonale Des Fous \\
\hline \multicolumn{5}{|l|}{ Demographic characteristics } \\
\hline \multicolumn{5}{|l|}{ Sex } \\
\hline Men & $2601(83.2)$ & $630(74.5)^{\#}$ & $498(78.7)^{\$}$ & $1468(89.5) *$ \\
\hline Women & $525(16.8)$ & $216(25.5)$ & $135(21.3)$ & $173(10.5) *$ \\
\hline Age (years) & $42(35-50)$ & $38(32-46) \#$ & $41(33-50)^{\$}$ & $44(38-50) *$ \\
\hline \multicolumn{5}{|l|}{ Place of residence } \\
\hline Réunion Island & $1605(52.0)$ & $596(71.0)$ & $420(66.9)^{\$}$ & $589(36.4) *$ \\
\hline Metropolitan France & $1310(42.5)$ & $208(24.8)$ & $179(28.5)$ & $923(57.0)$ \\
\hline Other country & $171(5.5)$ & $35(4.2)$ & $29(4.6)$ & $107(6.6)$ \\
\hline Living in a tropical climate & $1688(54.4)$ & $611(72.7)$ & $440(70 .)^{\$}$ & $635(39.1) *$ \\
\hline \multicolumn{5}{|l|}{ Morphological characteristics } \\
\hline \multicolumn{5}{|l|}{ Men } \\
\hline Mass (kg) & $71(66-76)$ & $72(66-77)$ & $71(66-76)$ & $71(66-75)$ \\
\hline Height $(\mathrm{cm})$ & $176(172-181)$ & $176(172-181)$ & $176(172-181)$ & $176(172-181)$ \\
\hline $\mathrm{BMI}(\mathrm{kg} / \mathrm{m} 2)$ & $22.8(21.5-24.2)$ & $22.9(21.5-24.3)$ & $22.6(21.4-24.2)$ & $22.7(21.5-24.0)$ \\
\hline Women & & & & \\
\hline Mass (kg) & $56(52-61)$ & $56(52-62)$ & $56(52-62)$ & $56(52-60)$ \\
\hline Height (cm) & $165(160-170)$ & $165(160-170)$ & $165(160-170)$ & $164(160-168)$ \\
\hline $\mathrm{BMI}(\mathrm{kg} / \mathrm{m} 2)$ & $20.7(19.6-22.0)$ & $20.8(19.5-22.2)$ & $20.7(19.3-22.2)$ & $20.7(19.8-21.7)$ \\
\hline \multicolumn{5}{|l|}{ Training characteristics } \\
\hline Trail running experience (yr) & $5(3-10)$ & $3(1-6)^{\#}$ & $5(3-9)^{\$}$ & $6(4-10) *$ \\
\hline $\begin{array}{l}\text { Number of ultra-races }>60 \mathrm{~km} \\
\text { ran throughout career }(n)\end{array}$ & $5(2-10)$ & $1(0-3) \#$ & $3(2-7)^{\$}$ & $8(4-13) *$ \\
\hline $\begin{array}{l}\text { Yearly number of ultra-races } \\
>>60 \mathrm{~km}(n / \mathrm{yr})\end{array}$ & $1(0.4-1.5)$ & $0.1(0-0.7)^{\#}$ & $0.9(0.5-1.3)^{\$}$ & $1.3(0.8-2.0)$ * \\
\hline \multicolumn{5}{|l|}{$\begin{array}{l}\text { Average weekly training (over the } \\
6 \text {-month period before the race) }\end{array}$} \\
\hline Duration $(\mathrm{h})$ & $8(5-10)$ & $6(4-8) \#$ & $7(5-10)^{\$}$ & $8(6-12) *$ \\
\hline Distance $(\mathrm{km})$ & $50(30-60)$ & $40(25-50) \#$ & $40(30-50)^{\$}$ & $50(40-70) *$ \\
\hline Ascent $(\mathrm{m})$ & $1200(700-2000)$ & $1000(500-1500) \#$ & $1000(700-2000)^{\$}$ & $1500(900-2000)$ * \\
\hline
\end{tabular}

Categorical variables are expressed as $n$ (percentages) and quantitative variables as medians (Q1-Q3). Percentages are calculated on the number of respondents for each variable. BMI = Body Mass Index. ${ }^{*}$ Comparisons between La Diagonale des Fous (DDF) vs. La Mascareignes (MAS), $\$$ comparisons between DDF vs. Le Trail de Bourbon (TDB), , comparisons between MAS vs. TDB. * $\$$, \# significant difference after Bonferroni correction.

\subsection{Survey}

The pre-race survey (Supplementary S1) contained questions on demographic characteristics and on trail-running and training experience, followed by specific questions on trail-running experience in hot environments, medical history of heat symptoms and heat illness before this race, and heat acclimatization before the race, and then by questions on planned hydration and cooling strategies. Cooling strategy was defined as any method used for reducing or preventing excessive heat storage during exercise. Only mid-cooling 
(i.e., cooling during the races) strategies used by runners were assessed. To help the runners answering, the main cooling methods were provided in the questionnaire (Supplementary S1). The post-race survey (Supplementary S2) looked at the impact of environmental conditions on performance, the occurrence of HRS during the race, and questions on effective hydration during the race. Planned hydration was asked in pre-race survey by "How amount of fluid do you plan to drink during the race? (in $\mathrm{mL} / \mathrm{h}$ )", and effective hydration was asked in post-race survey by "What amount of fluid did you drink during the race (in $\mathrm{mL} / \mathrm{h}$ )?" (Supplementaries S1 and S2). Data on runners (i.e., withdrawal status and finish time) were provided by the organizing committee of the Grand Raid de la Réunion.

\subsection{Statistical Analyses}

Qualitative variables were expressed as numbers and percentages, and quantitative variables were expressed as medians $(\mathrm{Q} 1-\mathrm{Q} 3)$ or means $\pm \mathrm{SD}$. Univariate analyses were performed using Pearson's chi-squared test for categorical variables, and the Student's t-test or the Mann-Whitney U test for quantitative variables as appropriate. The Kruskal-Wallis test and the Wilcoxon rank-sum test were performed to compare fluid volume consumption between the races. The significance level was set to $5 \%$. Bonferroni correction was applied to multiple comparisons. All analyses were performed using Stata V13 software (StataCorp LP, College Station, TX, USA).

\section{Results}

\subsection{Medical History of Heat Related Illness before This Race}

Before this race, $78 \%$ of participants reported a history of HRS; this value was higher in men than women $(79.9 \%$ vs. $70.2 \%, p<0.001)$, and higher in runners living in hot climates (HCR) than runners living in temperate climates (TCR) $(80.5 \%$ vs. $75.3 \%, p=0.003)$. A higher prevalence of a history of muscle cramps was found in men compared to women and in HCR compared to TCR $(p<0.001)$ (Table 2$)$. A total of $44(1.9 \%)$ runners reported a previous diagnosis of EHI; of these, $18(0.8 \%)$ had been hospitalized or had visited the emergency room and $4(0.2 \%)$ had received intensive care. A higher prevalence of heatrelated hospitalization was found in TCR compared to HCR $(p=0.021)$. No difference was found according to sex (Table 2).

\subsection{Heat Training and Acclimatization}

About one-quarter $(24.3 \%)$ of the 1033 TCR declared having trained in the heat. This value was similar between men and women $(21.8 \%$ vs. $24.8 \%, p=0.427)$ independently across the three races $(p=0.599)$. Most of these runners $(98.4 \%)$ used natural heat (length of preparation: 15 (10-30) days) while only five runners used a climatic chamber (length of preparation: 6 (3-9.5) days). Among TCR, 56.8\% declared having voluntarily scheduled an early arrival on the island to acclimatize to local environmental conditions (outside a holiday context), a proportion that was higher in women $(65.2 \%)$ than men $(55.2 \%$, $p=0.022$ ). However, the time to start of the race was only 4 (3-6) days with $6.8 \%$ of runners landing the day before the start of the race and $86.7 \%$ landing within 7 days before the race. No significant difference in arrival times before the race was found between TCR finishers and TCR non-finishers (4 (3-6) vs. 5 (3-6), respectively, $p=0.163$ ). 
Table 2. Previous history of symptoms and diagnosis of heat illness in the Grand Raid de la Réunion runners by total sample and according to sex and climate of residence.

\begin{tabular}{|c|c|c|c|c|c|}
\hline Variables & $\begin{array}{c}\text { Total } \\
(n=2286)\end{array}$ & $\begin{array}{c}\text { Women } \\
(n=410)\end{array}$ & $\begin{array}{c}\text { Men } \\
(n=1876)\end{array}$ & $\begin{array}{l}\text { Hot Climate } \\
(n=1250)\end{array}$ & $\begin{array}{c}\text { Temperate } \\
\text { Climate } \\
(n=1033)\end{array}$ \\
\hline History of heat-related symptoms & $1771(78.2)$ & $287(70.2)$ & $1484(79.9) *$ & $997(80.5) *$ & $771(75.3)$ \\
\hline Fatigue/performance decrease & $1318(58.2)$ & $226(55.3)$ & $1092(58.8)$ & $723(58.4)$ & $593(57.9)$ \\
\hline Muscle cramps & $852(37.6)$ & $92(22.5)$ & $760(40.9)^{*}$ & $551(44.5) *$ & $298(29.1)$ \\
\hline Digestive disorders & 361 (15.9) & $55(13.5)$ & $306(16.5)$ & $170(13.7) *$ & $191(18.7)$ \\
\hline Severe headache & $98(4.3)$ & $25(6.1)$ & $73(3.9)$ & $65(5.3)$ & $33(3.2)$ \\
\hline Collapse & $61(2.7)$ & $12(2.9)$ & $49(2.6)$ & $29(2.3)$ & $32(3.1)$ \\
\hline Other & $24(1.1)$ & $6(1.5)$ & $18(1.0)$ & $12(1.0)$ & $12(1.2)$ \\
\hline History of heat illness diagnosis & $43(1.9)$ & $4(1.0)$ & $39(2.1)$ & $20(1.6)$ & $23(2.2)$ \\
\hline Dehydration & $24(1.1)$ & 0 & $24(1.3)$ & $9(0.7)$ & $15(1.5)$ \\
\hline Hyponatremia & $3(0.1)$ & $2(0.5)$ & $1(0.05)$ & 0 & $3(0.3)$ \\
\hline Heat exhaustion & $6(0.3)$ & 0 & $6(0.3)$ & $3(0.2)$ & $3(0.3)$ \\
\hline Heat stroke & $14(0.6)$ & $2(0.5)$ & $12(0.6)$ & $6(0.5)$ & $8(0.8)$ \\
\hline Other & $6(0.3)$ & 0 & $6(0.3)$ & $4(0.3)$ & $2(0.2)$ \\
\hline Hospitalization & $18(0.8)$ & $4(1.0)$ & $14(0.8)$ & $5(0.4)$ & $13(1.3) *$ \\
\hline Intensive Care Unit hospitalization & $4(0.2)$ & $1(0.2)$ & $3(0.2)$ & $1(0.1)$ & $3(0.3)$ \\
\hline
\end{tabular}

Data are expressed as $n$ (percentages). All * refer to comparisons between (1) women vs. men, or (2) runners from hot climates vs. runners from temperate climates. Percentages are calculated on the number of respondents for each variable. ${ }^{*}$ Significant difference after Bonferroni correction.

\subsection{Cooling Strategy}

A cooling strategy during the race was reported by $45.1 \%$ of runners with no difference according to sex $(p=0.107)$ or climate of residence $(p=0.569)$ (Table 3$)$.

Table 3. Planned hydration and per-cooling strategies in the Grand Raid de la Réunion runners by total sample and according to sex and climate of residence.

\begin{tabular}{|c|c|c|c|c|c|}
\hline Variables & $\begin{array}{c}\text { Total } \\
(n=2286)\end{array}$ & $\begin{array}{l}\text { Women } \\
(n=410)\end{array}$ & $\begin{array}{c}\text { Men } \\
(n=1876)\end{array}$ & $\begin{array}{l}\text { Hot Climate } \\
(n=1250)\end{array}$ & $\begin{array}{c}\text { Temperate } \\
\text { Climate } \\
(n=1033)\end{array}$ \\
\hline Planned cooling strategy & $880(45.1)$ & $122(40.8)$ & $681(45.9)$ & $422(45.8)$ & $374(44.4)$ \\
\hline Stop/rest in the shade & $379(19.4)$ & $54(18.1)$ & $292(19.7)$ & $200(21.7)$ & $146(17.3)$ \\
\hline Wet sponge & $232(11.9)$ & $34(11.4)$ & $179(12.1)$ & $108(11.7)$ & $104(12.4)$ \\
\hline Leg immersion in cold water (creek, river) & $131(6.7)$ & $25(8.4)$ & $96(6.5)$ & $69(7.5)$ & $50(5.9)$ \\
\hline Shower/whole body immersion & $71(3.6)$ & $7(2.3)$ & $53(3.6)$ & $35(3.8)$ & $24(2.9)$ \\
\hline Head/neck cooling & $327(16.8)$ & $52(17.4)$ & $252(17.0)$ & $136(14.8)$ & $164(19.5)$ \\
\hline Cooling of other body area & $50(2.3)$ & $7(2.3)$ & $57(3.8)$ & $24(2.6)$ & $39(4.6)$ \\
\hline Cold towel & $80(4.1)$ & $7(2.3)$ & $64(4.3)$ & $44(4.8)$ & $26(3.1)$ \\
\hline Hat, cap, etc. & 239 (12.3) & $36(12.0)$ & $184(12.4)$ & $86(9.3)$ & $131(15.6) *$ \\
\hline Neck collar & $55(2.8)$ & $10(3.3)$ & $44(3.0)$ & $26(2.8)$ & $26(3.1)$ \\
\hline Ice slurry/water ingestion & $33(1.7)$ & $6(2.0)$ & $24(1.6)$ & $24(2.6) *$ & $5(0.6)$ \\
\hline Ice vest & $5(0.3)$ & 0 & $5(0.3)$ & $3(0.3)$ & $1(0.1)$ \\
\hline Other & $23(1.2)$ & $2(0.7)$ & $18(1.2)$ & $12(1.3)$ & $8(1.0)$ \\
\hline \multicolumn{6}{|l|}{ Planned fluid consumption } \\
\hline Pure Water & $1688(75.3)$ & $299(74.2)$ & $1389(75.5)$ & $968(78.4) *$ & $720(71.4)$ \\
\hline Sodium-enriched water & $701(31.3)$ & $96(23.8)$ & $605(32.9)^{*}$ & $350(28.3)$ & $351(34.8)$ * \\
\hline Homemade preparation & 306 (13.6) & $66(16.4)$ & $240(13.0)$ & $207(16.8)$ * & $99(9.8)$ \\
\hline Exercise drink & $1341(59.8)$ & $222(55.1)$ & $1119(60.8)$ & $733(59.4)$ & $608(60.3)$ \\
\hline Other & $416(18.6)$ & $80(19.9)$ & $336(18.3)$ & $242(19.6)$ & $174(17.3)$ \\
\hline Pure water alone (no other beverage) & $237(10.6)$ & $44(10.9)$ & $193(10.5)$ & $121(9.8)$ & $116(11.5)$ \\
\hline
\end{tabular}

Data are expressed as $n$ (percentages). All * refer to comparisons between (1) women vs. men, or (2) runners from hot climates vs. runners from temperate climates. Percentages are calculated on the number of respondents for each variable. ${ }^{*}$ Significant difference after Bonferroni correction. 


\subsection{Heat Related Symptoms during the Races}

The post-race survey revealed that $23.8 \%$ of runners suffered from the heat during the race; this value was similar according to sexes $(p=0.898)$ but higher in HCR than TCR $(25.8 \%$ vs. $19.9 \%, p=0.003)$. These findings were consistent across the three races. A similar proportion of runners (20.2\%) thought that the heat had negatively impacted their performance, without reaching the level of significance between HCR and TCR $(p=0.078)$. Up to $54.6 \%$ of the runners reported at least one HRS; this value was higher in men than in women $(56.5 \%$ vs. $46.8 \%, p=0.002)$ but did not vary according to climate of residence $(p=0.603)$. Runners declared the following HRS: muscle cramping $(43.4 \%)$, digestive disorder $(14.3 \%)$, collapse $(1.2 \%)$, and severe headache $(0.9 \%)$. A detailed list of HRS according to sex is provided in Figure 1.

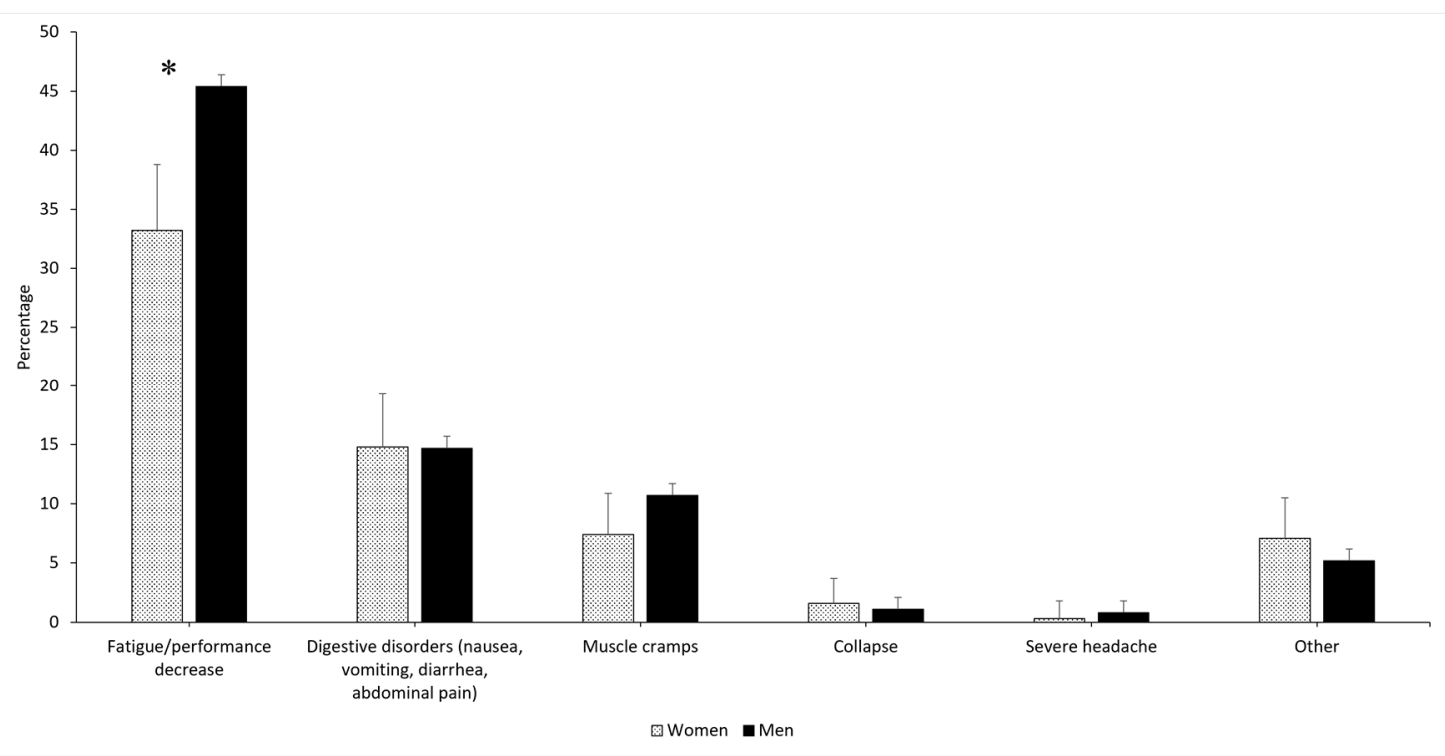

Figure 1. Heat-related symptoms experienced during the race by Grand Raid de la Réunion runners according to sex. * Significant difference between men and women.

\subsection{Hydration}

The hydration rate planned by runners was $663 \pm 240 \mathrm{~mL} / \mathrm{h}$ (corresponding to $9.7 \pm$ $3.7 \mathrm{~mL} / \mathrm{kg} / \mathrm{h})$ for the whole population $(686 \pm 237 \mathrm{~mL} / \mathrm{h}$ for MAS vs. $640 \pm 235 \mathrm{~mL} / \mathrm{h}$ for TDB vs. $661 \pm 242 \mathrm{~mL} / \mathrm{h}$ for DDF $(p=0.018))$. This rate was $624 \pm 229 \mathrm{~mL} / \mathrm{h}$ for women vs. $671 \pm 241 \mathrm{~mL} / \mathrm{h}$ for men $(p=0.002)$ (see repartition per race in Figure $2 \mathrm{~A}$ ), and $635 \pm 236 \mathrm{~mL} / \mathrm{h}$ for non-finishers vs. $671 \pm 240 \mathrm{~mL} / \mathrm{h}$ for finishers $(p=0.009)$. No differences in planned hydration volume were found according to climate of residence $(p=0.569)$. More men than women planned to drink sodium-enriched water (33 vs. $24 \%$, $p<0.001$ ) (Table 3). The consumption of pure water or homemade preparation was more prevalent in HCR $(p<0.001)$, whereas the consumption of sodium-enriched water was more prevalent in TCR $(p<0.001)$. Ten percent of runners planned to drink only pure water during the races, namely $13.5 \%$ of MAS runners vs. $11.0 \%$ of TDB runners vs. $9.0 \%$ of DDF runners $(p=0.013)$. Repartition of beverage composition extrapolated on a 1-L bottle is illustrated in Figure 2C. Qualitative analysis of the variables "homemade preparation" and "other kind of beverage" found that $24.0 \%$ of runners planned to add carbohydrates to their beverage, $12.6 \%$ planned to consume sparkling beverages, and $11.9 \%$ planned to consume soda drinks. 


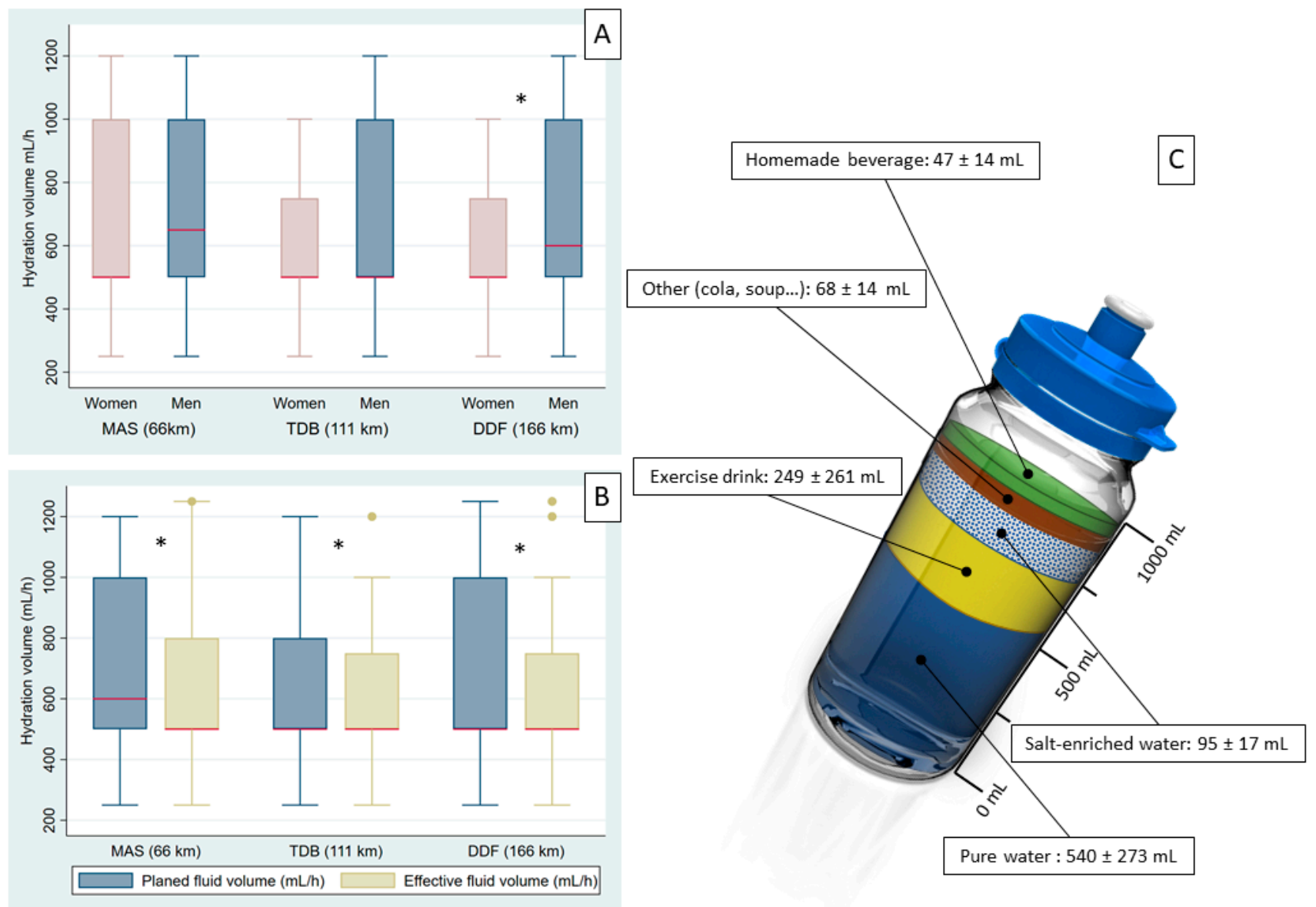

Figure 2. Hydration strategies of runners of the "Grand Raid de la Réunion" 2019 edition. MAS: La Mascareignes, TDB: Le Trail de Bourbon, DDF: La Diagonale des Fous. (A) Hydration volume in $\mathrm{mL} / \mathrm{h}$ according to race and sex. * Significant difference between men and women. (B) Planned and effective hydration volume in $\mathrm{mL} / \mathrm{h}$ reported by runners according to race. * Significant difference between planned and effective hydration volume. (C) Distribution of beverage types extrapolated on a 1-L bottle. Data are presented in milliliters $(\mathrm{mL})$ with mean $\pm \mathrm{SD}$.

Overall, $77.0 \%$ of runners declared having a hydration strategy; this value was higher in HCR than TCR $(79.9 \%$ vs. $74.9 \%, p=0.013)$, but did not vary according to sex $(p=0.518)$. Drinking to thirst was declared by $39.2 \%$ of runners. Other factors determining runners' hydration were color of urines $(10.9 \%)$, and maximum tolerated hydration $(6.4 \%)$. The value of hydration volume reported post-race was $61 \pm 244 \mathrm{~mL} / \mathrm{h}$ lower than the value planned by the runners pre-race $(p<0.0001)$; this difference was consistent across the three races (Figure 2B). According to the post-race survey, $80.3 \%$ of runners considered their hydration to be sufficient; this value was lower in women than men $(73.9 \%$ vs. $81.5 \%$, respectively, $p=0.002)$ but did not vary according to climate of residence $(p=0.301)$. Moreover, $58.8 \%$ of the runners added sodium to their food or beverage during the race; this value was higher in HCR than TCR $(62.9 \%$ vs. $53.8 \%, p<0.001)$ but did not vary according to sex difference $(p=0.585)$. The proportion of runners $(51.8 \%)$ who ate soup during the race was similar between HCR and TCR.

\section{Discussion}

The main results of the present study are that (i) although $78 \%$ of ultra-endurance runners had a previous history of HRS, $1.9 \%$ declared a medical history of EHI; (ii) only one quarter of TCR reported having specifically trained in the heat, yet the prevalence of self-declared negative impact of environmental conditions in performance $(20 \%)$ and HRS incidence (54.6\%) was not higher for TCR compared to HCR; (iii) three quarter of 
all participants had a hydration strategy, with thirst representing a hydration signal for $39 \%$ of them, and $59 \%$ of runners added sodium to their food or beverage during the race. To our knowledge, this is the first study describing the heat mitigation strategies in ultra-endurance runners before a race in a tropical environment.

\subsection{History of Heat-Related Symptoms and Exertional Heat Illness}

Three-quarters of participants reported a history of HRS before this race, which is higher than what has been reported by elite athletes $(48 \%)$ and elite cyclists $(57 \%)[25,26]$. Conversely, forty-four runners $(2 \%)$ of the athletes participating in the present study reported a history of EHI, leading to hospitalization or emergency consulting in $18(0.8 \%)$ of them. This prevalence is lower than in previous cross-sectional study in elite athletes (16\% in road cycling [26] and 9\% in athletics [25]). This relatively low EHI prevalence in ultra-endurance running compared to other sports must be confirmed by prospective epidemiological studies but can partially be explained by the fact that exercise intensity is at least as important as environmental conditions for increasing core temperature $[19,26]$. Another explanation can be found in the "flush model" developed by Millet [27]. In his holistic model, the author suggests that elite athletes (who are very rare in ultra-trail pelotons) could finish the race with a lower security reserve (i.e., a reserve allowing one to prevent physiological damage) and therefore could be more exposed to EHI in hot and humid environments than amateur ultra-endurance runners [27]. Finally, a relative low prevalence of EHI compared to HRS declared by runners could be related to an underdiagnosis of the true rate of EHI [28]. Given the frequent failure to measure core body temperature during races, it is plausible that some events could be erroneously attributed to cardiac conditions based on incidental pathological findings, whereas heat stroke was the real etiology. A previous study suggested that serious cardiac events were outnumbered by heat stroke events by a factor of 10 during endurance sport [29].

\subsection{Heat Training and Acclimatization}

Heat acclimatization is considered as the most important countermeasure to protect the health of athletes and to enhance their performance in hot conditions [6,30]. Ideally, the heat acclimatization period should pass 2 weeks in order to maximize all benefits [6]. In our study, only one-quarter of TCR reported having trained in the heat (mostly in natural environments) before the event, with an average training duration of 15 days. This percentage is higher than that observed in the high-performance athletes who participated in the 2015 IAAF Worlds Athletics Championships held in Beijing (15\%) [25]. The comparison with the Worlds Athletics Championships study must however be made with caution because this study included track and field athletes for which heat acclimatization is less important [6]. Considering the repercussions of heat stress on endurance performance $[14,31,32]$, and given the fact that heat acclimatization can reduce the likelihood of heat illness [20], one may wonder why so few runners in our study acclimatized before the event. We suggest two possible explanations for this. First, this may be due a lack of awareness of the potential risks in this population due to the scarcity of epidemiological data on the prevalence of $\mathrm{EHI}$ in ultra-endurance running and to the absence of guidelines and recommendations for ultra-endurance runners [13]. Second, ultra-endurance runners are mostly amateurs with a limited possibility to organize training camps. In our study, $42 \%$ of the runners who had trained in the heat before the event reported a training duration less than 14 days. Half of our eligible population was made up of runners from metropolitan France, where the climate is temperate (mean temperature in October 2019 was $15.1^{\circ} \mathrm{C}$ ), making optimal heatacclimatization difficult. The time required to achieve optimal acclimatization likely varies, but a total period of 2 weeks has been shown to facilitate maximal adaptations [6,33,34]. In our study, the time to start of the race was only 4 days. In the present study, no significant difference in arrival times before the race was found between TCR finishers and TCR non-finishers $(p=0.163)$. 


\subsection{Cooling Strategy}

While several reviews concluded that cooling can increase prolonged exercise capacity in hot conditions [34,35], only $45 \%$ of ultra-endurance runners in our study used cooling strategies during the race. This proportion is lower than mid-cooling strategy using prevalence (98\%) found in elite road race athletes during the Doha 2019 IAAF World Athletics Championships [36]. In our study, runners used mostly external cooling strategies, namely natural cooling strategies (leg $(7 \%)$ or whole-body $(4 \%)$ immersion in creeks or rivers, resting in the shade $(19 \%)$ ) and classic strategies (wet sponge $(12 \%)$, head/neck cooling $(17 \%)$, hat, cap $(12 \%)$, cold towel $(4 \%)$, neck collar $(3 \%))$.

\subsection{Heat Related Symptoms during the Races}

During the races, $24 \%$ of runners declared having suffered from the heat, and only $20 \%$ stated that the heat had negatively impacted their performance. This relative low prevalence of perceived heat repercussions may be partly due to the relatively mild conditions that prevailed during this edition of the Grand Raid de la Réunion, with temperatures not exceeding $30^{\circ} \mathrm{C}$ (range 3.6 to $29.7^{\circ} \mathrm{C}$ ) and humidity remaining at usual levels $(75 \%)$. This was in fact the coolest edition of the last 6 years (range $5.8-32.3^{\circ} \mathrm{C}$ ). Importantly, only 61 non-finishers answered the post-race survey (accounting for $3 \%$ of all completed post-race survey), which contained questions on HRS during the race. Considering that the proportion of non-finisher of the three races of the 2019 edition was $28 \%$, heat repercussions during races were most probably underestimated. In future studies, data should be collected from the onsite medical team and from local hospitals to determine the prevalence of EHI during the race. Up to $55 \%$ of the runners reported at least one HRS, which is surprising given that only $20 \%$ of the runners stated that the heat had negatively impacted their performance. The reasons are unclear. This gap may be explained by the fact that respondents reporting symptoms were not due to the heat but to other issues (injuries, sleep deprivation, etc.), even though the survey question was explicitly about HRS. It is also possible that runners had symptoms but considered that it did not limit their performance (i.e., they considered to be limited by other factors). This may be further exacerbated by declarative bias, i.e., runners would appear strong and declare symptoms without mentioning it was influencing their performance. Although only a quarter of athletes of TCR reported having trained specifically in the heat, similar prevalence of negative impact of environmental conditions in performance $(\sim 20 \%)$ and HRS incidence $(55 \%)$ during races were declared according to climate of residence. Moreover, a higher percentage of HCR declared having suffered from the heat $(25.8 \%$ vs. $19.9 \%, p=0.003)$. This unexpected difference could be partly explained by the date of the race and the importance of seasonal acclimatization. The race took place in mid-October, just after the end of summer for the inhabitants of the northern hemisphere, but just before the start of the hot season (November) for local residents (mean temperature in October 2019 in Réunion Island was $22^{\circ} \mathrm{C}$ ). Although temperatures in France were only $15{ }^{\circ} \mathrm{C}$ at the time of the race, the temperature in the month preceding the events could rise to above $25^{\circ} \mathrm{C}$, allowing the TCR runners to repeatedly train in warm environments. Residing in a hot climate may not confer an advantage if one has not been yet exposed to heat for many months, i.e., has not benefited from seasonal acclimatization of a hot season as was the case from the runners from La Réunion, i.e., the vast majority of our HCR population [5]. This is critical, as seasonal acclimatization is important in protecting athletes' health when practicing in the heat. Indeed, it has been shown that the risk of heat related collapse was higher at the beginning than the middle of the summer when athletes had not yet acquired natural acclimatization to heat [37]. Moreover, a recent study of analysis of heat illness in the Beach Volleyball World Tour showed that there were more medical time-outs related to the heat during competition in Asia in the winter when northern hemisphere players do not benefit anymore from seasonal acclimation [5]. 


\subsection{Hydration}

Data on hydration strategies during ultra-endurance running remain scarce [13]. In our study, $77.0 \%$ of runners declared having a hydration strategy, with a planned hydration rate of $663 \mathrm{~mL} / \mathrm{h}$ (corresponding to $9.7 \pm 3.7 \mathrm{~mL} / \mathrm{kg} / \mathrm{h}$ ), with a higher hydration rate in shorter races: $686 \pm 237 \mathrm{~mL} / \mathrm{h}$ for MAS $(65 \mathrm{~km})$ vs. $640 \pm 235 \mathrm{~mL} / \mathrm{h}$ for TDB $(111 \mathrm{~km})$ vs. $661 \pm 242 \mathrm{~mL} / \mathrm{h}$ for DDF $(165 \mathrm{~km})(p=0.018)$. These results are in line with recent publications in ultra-endurance running reporting a mean hydration volume of 685 [38] and $732 \mathrm{~mL} / \mathrm{h}$ [39]. Past consensus statements recommended minimizing fluid deficit; however, debates continue as to how athletes should hydrate during exercise, i.e., ad libitum vs. pre-programmed drinking schedule [18]. The typical hydration guidelines to avoid more than $2 \%$ body mass loss may not apply in ultra-endurance activities [12]. In our sample, thirst was the factor determining hydration for only $39 \%$ of runners; the other factors were color of urine for $11 \%$ and maximum tolerated hydration for $6 \%$ of the runners. Recent considerations of hydration concluded that ultra-endurance runners should be cautious to avoid drinking beyond the dictate of thirst and taking in excessive sodium during prolonged exercises [12]. Whilst hyperhydration can lead to exercise associated hyponatremia, hypohydration during exercise in hot ambient conditions can increase the risk of developing EHI [40]. Moreover, pronounced dehydration associated with influx of muscle protein (myoglobin) caused by muscle damage may lead to kidney damage. The prevalence of an acute kidney insult in ultra-marathon running is nearly $45 \%$ of all runners [41].

A wide range of hydration strategies was observed in our population. Most runners (75.3\%) had planned to drink water; $59.8 \%$ had planned to consume exercise drinks, almost $60 \%$ had planned to consume sodium-enriched water or food, $24 \%$ had planned to consume carbohydrate-enriched water or food, and $10 \%$ of the runners declared drinking exclusively pure water during the race. Hydration and nutrition recommendations commonly prescribe sodium and carbohydrate ingestion during prolonged endurance exercise in the heat [42]. However, sodium supplementation should not be aimed at replacing all losses and should not be excessive during ultra-endurance activities, as sodium consumption in the typical race diet of ultra-endurance runners appears to be adequate [12].

In our study, the heterogeneity of hydration practices is reflected in the extreme diversity of products that were added to homemade preparations by runners: coffee or tea, fruit juice, spices, milk, plants or herbs, proteins, amino acid supplements, etc. Of note, the challenges of endurance sports include the potential for large variations in ambient conditions during a single event, and practical considerations include the availability of nutrition supplies at aid stations, the difficulties of ingestion during exercise, and the interaction with gastrointestinal comfort/function [42]. Specific recommendations are needed regarding hydration volume and drink content during ultra-endurance running adapted to (i) individual tastes and avoidance of loss of appetence, and (ii) the practical considerations associated with each race (autonomy or semi-autonomy).

\subsection{Study Strengths and Limitations}

The low rate of response to the post-race survey among non-finishers may have biased our analysis of the effects of hot and humid conditions on ultra-endurance running. As this study is a survey-based study, it is subject to the declarative bias of athletes. It remains possible that despite the specify of the questions regarding HRS and HRI, some runners attributed to heat some conditions being not heat-related. Comparisons of prevalence made with the prevalence of other disciplines or other papers should therefore be considered with caution due to the lack of clinical data in our study to confirm the self-assessment of the runners. However, our study provides a relevant estimation of the burden of EHI self-reported in ultra-endurance running, a discipline poorly investigated. Nevertheless, a major strength of the present study is its total sample size $(n=3317)$ and representativeness, as $56 \%$ of the total eligible population was included in at least one of the two surveys (preand post-race surveys). Environmental conditions during the race were not extreme due to 
relatively low temperatures; since runners did not know ahead of time what environmental conditions would be like, our findings concerning the strategies they employed (as declared on the pre-race survey) can be considered as representative of the population.

\section{Conclusions}

The present study shows that ultra-endurance runners have a wide variability of hydration and heat preparation strategies. However, although consensus recommendations on training and competing in the heat are only partially adopted by ultra-endurance runners, prevalence of EHI remains low in ultra-endurance, probably because exercise intensity is a more potent parameter for increasing body temperature than environmental parameters. Being native as a resident of tropical country seems not to confer an advantage in reducing the negative impact of heat on performance and HRS incidence if the athletes have not been exposed to heat in the weeks preceding the race (i.e., no seasonal acclimatization). In our study, $3 / 4$ of runners declared having a hydration strategy, with a planned hydration volume of about $650 \mathrm{~mL} / \mathrm{h}$. Thirst represented the hydration signal for $40 \%$ of ultra-endurance runners, and $60 \%$ of them added sodium to their food or beverage. Recent considerations recommending that ultra-endurance runners should be cautioned to avoid drinking beyond the dictate of thirst and taking in excessive sodium during prolonged exercises are only partially respected. Understandings of heat stress repercussions in ultra-endurance running need to be improve by specific field research.

\section{Practical Implications}

- Information of the ultra-endurance runners about benefits of heat acclimatization and cooling strategies before running in hot and humid conditions is needed.

- Prevalence of EHI remains low in ultra-endurance based on declarative evaluation in this study. However, prospective studies with clinical assessment of EHI (core temperature, symptoms) to better estimate the burden of heat stress in ultra-endurance disciplines are needed.

- The importance of hydration requirements in hot and humid conditions in ultraendurance running needs to be kept in mind.

Supplementary Materials: The following are available online at https: / www.mdpi.com/article / 10.3390/nu13041085/s1, Supplementary S1: Pre-race survey (French version), Supplementary S2: Post-race survey (French version).

Author Contributions: Conceptualization, N.B., G.Y.M. and S.R.; methodology, N.B., G.Y.M. and S.R.; formal analysis, N.B. and R.F.; investigation, N.B.; data curation, N.B. and R.F.; writing-original draft preparation, N.B.; writing-review and editing, N.B., G.Y.M. and S.R.; supervision, G.Y.M. and S.R. All authors have read and agreed to the published version of the manuscript.

Funding: This research received no external funding.

Institutional Review Board Statement: This study was approved by the Saint-Etienne University Hospital ethics committee (\#IRBN 572019/CHUSTE) and registered in https: / / www.clinicaltrials. gov/ct2/show/NCT04136925 (accessed on 25 March 2021). The data were collected, recorded, and stored after obtained consent from the research subjects and were included in the register of processing activities of the Réunion Island University Hospital Center.

Informed Consent Statement: Informed consent was obtained from all subjects involved in the study.

Data Availability Statement: The data presented in this study are available on reasonable request from the corresponding author.

Acknowledgments: This study was supported by the Réunion Island University Hospital Center. The author would like to thank Arianne Dorval for proofreading the manuscript as well as all the medical students of the Réunion Island University Hospital Center who participated in data collection.

Conflicts of Interest: The authors declare no conflict of interest. 


\section{References}

1. Gamage, P.J.; Fortington, L.V.; Finch, C.F. Epidemiology of Exertional Heat Illnesses in Organised Sports: A Systematic Review. J. Sci. Med. Sport 2020, 23, 701-709. [CrossRef]

2. Filep, E.M.; Murata, Y.; Endres, B.D.; Kim, G.; Stearns, R.L.; Casa, D.J. Exertional Heat Stroke, Modality Cooling Rate, and Survival Outcomes: A Systematic Review. Medicina 2020, 56, 589. [CrossRef] [PubMed]

3. Bouchama, A.; Knochel, J.P. Heat Stroke. N. Engl. J. Med. 2002, 346, 1978-1988. [CrossRef]

4. Leon, L.R.; Bouchama, A. Heat Stroke. Compr. Physiol. 2015, 5, 611-647. [CrossRef] [PubMed]

5. Racinais, S.; Alhammoud, M.; Nasir, N.; Bahr, R. Epidemiology and Risk Factors for Heat Illness: 11 Years of Heat Stress Monitoring Programme Data from the FIVB Beach Volleyball World Tour. Br. J. Sports Med. 2020. [CrossRef] [PubMed]

6. Racinais, S.; Alonso, J.M.; Coutts, A.J.; Flouris, A.D.; Girard, O.; González-Alonso, J.; Hausswirth, C.; Jay, O.; Lee, J.K.W.; Mitchell, N.; et al. Consensus Recommendations on Training and Competing in the Heat. Br. J. Sports Med. 2015, 49, 1164-1173. [CrossRef]

7. Bergeron, M.F.; Bahr, R.; Bärtsch, P.; Bourdon, L.; Calbet, J.A.L.; Carlsen, K.H.; Castagna, O.; González-Alonso, J.; Lundby, C.; Maughan, R.J.; et al. International Olympic Committee Consensus Statement on Thermoregulatory and Altitude Challenges for High-Level Athletes. Br. J. Sports Med. 2012, 46, 770-779. [CrossRef]

8. Cheuvront, S.N.; Haymes, E.M. Thermoregulation and Marathon Running: Biological and Environmental Influences. Sports Med. 2001, 31, 743-762. [CrossRef]

9. Bergeron, M.F. Heat Stress and Thermal Strain Challenges in Running. J. Orthop. Sports Phys. Ther. 2014, 44, 831-838. [CrossRef]

10. Bouscaren, N.; Millet, G.Y.; Racinais, S. Heat Stress Challenges in Marathon vs. Ultra-Endurance Running. Front. Sports Act. Living 2019, 1, 59. [CrossRef]

11. Knechtle, B.; Nikolaidis, P.T. Physiology and Pathophysiology in Ultra-Marathon Running. Front. Physiol. 2018, 9, 634. [CrossRef]

12. Hoffman, M.; Stellingwerff, T.; Costa, R.J.S. Considerations for Ultra-Endurance Activities: Part 2-Hydration. Res. Sports Med. 2019, 27, 182-194. [CrossRef]

13. Hoffman, M.D. State of the Science on Ultramarathon Running After a Half Century: A Systematic Analysis and Commentary. Int. J. Sports Physiol. Perform. 2020, 15, 1052-1056. [CrossRef]

14. Parise, C.A.; Hoffman, M.D. Influence of Temperature and Performance Level on Pacing a 161 Km Trail Ultramarathon. Int. J. Sports Physiol. Perform. 2011, 6, 243-251. [CrossRef]

15. Knechtle, B.; Gnädinger, M.; Knechtle, P.; Imoberdorf, R.; Kohler, G.; Ballmer, P.; Rosemann, T.; Senn, O. Prevalence of ExerciseAssociated Hyponatremia in Male Ultraendurance Athletes. Clin. J. Sport Med. Off. J. Can. Acad. Sport Med. 2011, 21, $226-232$. [CrossRef]

16. Seal, A.D.; Anastasiou, C.A.; Skenderi, K.P.; Echegaray, M.; Yiannakouris, N.; Tsekouras, Y.E.; Matalas, A.L.; Yannakoulia, M.; Pechlivani, F.; Kavouras, S.A. Incidence of Hyponatremia During a Continuous 246-Km Ultramarathon Running Race. Front. Nutr. 2019, 6, 161. [CrossRef] [PubMed]

17. Rehrer, N.J. Fluid and Electrolyte Balance in Ultra-Endurance Sport. Sports Med. 2001, 31, 701-715. [CrossRef]

18. Goulet, E.D.B.; Hoffman, M.D. Impact of Ad Libitum Versus Programmed Drinking on Endurance Performance: A Systematic Review with Meta-Analysis. Sports Med. 2019, 49, 221-232. [CrossRef] [PubMed]

19. Valentino, T.R.; Stuempfle, K.J.; Kern, M.; Hoffman, M.D. The Influence of Hydration on Thermoregulation During a 161-Km Ultramarathon. Wilderness Environ. Med. 2015, 26, e3. [CrossRef]

20. Racinais, S.; Casa, D.; Brocherie, F.; Ihsan, M. Translating Science Into Practice: The Perspective of the Doha 2019 IAAF World Championships in the Heat. Front. Sports Act. Living 2019, 1, 39. [CrossRef] [PubMed]

21. Kenefick, R.W. Drinking Strategies: Planned Drinking Versus Drinking to Thirst. Sports Med. 2018, 48, 31-37. [CrossRef] [PubMed]

22. Casa, D.J.; DeMartini, J.K.; Bergeron, M.F.; Csillan, D.; Eichner, E.R.; Lopez, R.M.; Ferrara, M.S.; Miller, K.C.; O'Connor, F.; Sawka, M.N.; et al. National Athletic Trainers' Association Position Statement: Exertional Heat Illnesses. J. Athl. Train. 2015, 50, $986-1000$. [CrossRef]

23. Hoffman, M.D.; Stuempfle, K.J. Is Sodium Supplementation Necessary to Avoid Dehydration During Prolonged Exercise in the Heat? J. Strength Cond. Res. 2016, 30, 615-620. [CrossRef]

24. Hoffman, M.D.; Stuempfle, K.J. Hydration Strategies, Weight Change and Performance in a 161 Km Ultramarathon. Res. Sports Med. 2014, 22, 213-225. [CrossRef]

25. Périard, J.D.; Racinais, S.; Timpka, T.; Dahlström, Ö.; Spreco, A.; Jacobsson, J.; Bargoria, V.; Halje, K.; Alonso, J.-M. Strategies and Factors Associated with Preparing for Competing in the Heat: A Cohort Study at the 2015 IAAF World Athletics Championships. Br. J. Sports Med. 2017, 51, 264-270. [CrossRef]

26. Racinais, S.; Moussay, S.; Nichols, D.; Travers, G.; Belfekih, T.; Schumacher, Y.O.; Periard, J.D. Core Temperature up to $41.5^{\circ} \mathrm{C}$ during the UCI Road Cycling World Championships in the Heat. Br. J. Sports Med. 2019, 53, 426-429. [CrossRef]

27. Millet, G.Y. Can Neuromuscular Fatigue Explain Running Strategies and Performance in Ultra-Marathons? Sports Med. 2011, 41, 489-506. [CrossRef]

28. Driscoll, T.R.; Cripps, R.; Brotherhood, J.R. Heat-Related Injuries Resulting in Hospitalisation in Australian Sport. J. Sci. Med. Sport 2008, 11, 40-47. [CrossRef] [PubMed]

29. Yankelson, L.; Sadeh, B.; Gershovitz, L.; Werthein, J.; Heller, K.; Halpern, P.; Halkin, A.; Adler, A.; Steinvil, A.; Viskin, S. Life-Threatening Events during Endurance Sports: Is Heat Stroke More Prevalent than Arrhythmic Death? J. Am. Coll. Cardiol. 2014, 64, 463-469. [CrossRef] [PubMed] 
30. Périard, J.D.; Racinais, S.; Sawka, M.N. Adaptations and Mechanisms of Human Heat Acclimation: Applications for Competitive Athletes and Sports. Scand. J. Med. Sci. Sports 2015, 25 (Suppl. 1), 20-38. [CrossRef]

31. Guy, J.H.; Deakin, G.B.; Edwards, A.M.; Miller, C.M.; Pyne, D.B. Adaptation to Hot Environmental Conditions: An Exploration of the Performance Basis, Procedures and Future Directions to Optimise Opportunities for Elite Athletes. Sports Med. 2015, 45, 303-311. [CrossRef]

32. Ely, M.R.; Cheuvront, S.N.; Roberts, W.O.; Montain, S.J. Impact of Weather on Marathon-Running Performance. Med. Sci. Sports Exerc. 2007, 39, 487-493. [CrossRef] [PubMed]

33. Racinais, S.; Périard, J.D.; Karlsen, A.; Nybo, L. Effect of Heat and Heat Acclimatization on Cycling Time Trial Performance and Pacing. Med. Sci. Sports Exerc. 2015, 47, 601-606. [CrossRef]

34. Tyler, C.J.; Sunderland, C.; Cheung, S.S. The Effect of Cooling Prior to and during Exercise on Exercise Performance and Capacity in the Heat: A Meta-Analysis. Br. J. Sports Med. 2015, 49, 7-13. [CrossRef]

35. Bongers, C.C.W.G.; Thijssen, D.H.J.; Veltmeijer, M.T.W.; Hopman, M.T.E.; Eijsvogels, T.M.H. Precooling and Percooling (Cooling during Exercise) Both Improve Performance in the Heat: A Meta-Analytical Review. Br. J. Sports Med. 2015, 49, 377-384. [CrossRef]

36. Racinais, S.; Ihsan, M.; Taylor, L.; Cardinale, M.; Adami, P.E.; Alonso, J.M.; Bouscaren, N.; Buitrago, S.; Esh, C.J.; Gomez-Ezeiza, J.; et al. Hydration and Cooling in Elite Athletes: Relationship with Performance, Body Mass Loss and Body Temperatures during the Doha 2019 IAAF World Athletics Championships. Br. J. Sports Med. 2021. [CrossRef]

37. Gosling, C.M.; Gabbe, B.J.; McGivern, J.; Forbes, A.B. The Incidence of Heat Casualties in Sprint Triathlon: The Tale of Two Melbourne Race Events. J. Sci. Med. Sport 2008, 11, 52-57. [CrossRef]

38. Lavoué, C.; Siracusa, J.; Chalchat, É.; Bourrilhon, C.; Charlot, K. Analysis of Food and Fluid Intake in Elite Ultra-Endurance Runners during a 24-h World Championship. J. Int. Soc. Sports Nutr. 2020, 17, 36. [CrossRef] [PubMed]

39. Costa, R.J.; Teixeira, A.; Rama, L.; Swancott, A.J.; Hardy, L.D.; Lee, B.; Camões-Costa, V.; Gill, S.; Waterman, J.P.; Freeth, E.C.; et al. Water and Sodium Intake Habits and Status of Ultra-Endurance Runners during a Multi-Stage Ultra-Marathon Conducted in a Hot Ambient Environment: An Observational Field Based Study. Nutr. J. 2013, 12, 13. [CrossRef] [PubMed]

40. Sawka, M.N.; Cheuvront, S.N.; Kenefick, R.W. Hypohydration and Human Performance: Impact of Environment and Physiological Mechanisms. Sports Med. 2015, 45 (Suppl. 1), 51-60. [CrossRef] [PubMed]

41. Lipman, G.S.; Shea, K.; Christensen, M.; Phillips, C.; Burns, P.; Higbee, R.; Koskenoja, V.; Eifling, K.; Krabak, B.J. Ibuprofen versus Placebo Effect on Acute Kidney Injury in Ultramarathons: A Randomised Controlled Trial. Emerg. Med. J. EMJ 2017, 34, 637-642. [CrossRef]

42. McCubbin, A.J.; Allanson, B.A.; Caldwell Odgers, J.N.; Cort, M.M.; Costa, R.J.S.; Cox, G.R.; Crawshay, S.T.; Desbrow, B.; Freney, E.G.; Gaskell, S.K.; et al. Sports Dietitians Australia Position Statement: Nutrition for Exercise in Hot Environments. Int. J. Sport Nutr. Exerc. Metab. 2020, 30, 83-98. [CrossRef] [PubMed] 